\title{
Faktor-Faktor Yang Mempengaruhi Fraudulent Financial Reporting
}

\author{
Wulanda Maya Sari', Anik Irawati ${ }^{*}$ \\ 1,2Institut Informatika dan Bisnis Darmajaya \\ 1wulandamayasari@gmail.com,2anikirawati@darmajaya.ac.id \\ ${ }^{*}$ Penulis korespondensi
}

\begin{abstract}
This study aims to empirically prove the influence of financial stability, external pressure, and ineffective monitoring on fraudulent financial reporting. Financial stability was measured using a comparison of total assets. External pressure was measured using leverage. Meanwhile, ineffective monitoring was measured using the ratio of independent commissioners' number. The dependent variable in this study was fraudulent financial reporting. It was measured using the F-Score Model. The sample in this study were 21 State Owned Enterprises (BUMN) listed on Indonesia Stock Exchange in period of 2017-2019. The data analysis method used in this study was Logistic Regression using SPSS software version 20. The results of this study indicate that financial stability has no influence on fraudulent financial reporting. Meanwhile, external pressure and ineffective monitoring influence fraudulent financial reporting.
\end{abstract}

Keywords: Financial stability, external pressure, ineffective monitoring, fraudulent financial reporting

\begin{abstract}
Abstrak
Penelitian ini bertujuan untuk membuktikan secara empiris pengaruh stabilitas keuangan, external pressure, dan ineffective monitoring terhadap fraudulent financial reporting. Stabilitas keuangan diukur menggunakan perbandingan total aset. External pressure diukur menggunakan leverage, sedangkan ineffective monitoring diukur menggunakan rasio jumlah dewan komisaris independen. Variabel dependen yaitu fraudulent financial reporting diukur menggunakan F-Score model. Sampel penelitian ini adalah 21 perusahaan Badan Usaha Milik Negara (BUMN) yang terdaftar di Bursa Efek Indonesia (BEI) dalam periode 2017 hingga 2019. Metode analisis data yang digunakan dalam penelitian ini yaitu regresi logistik dengan menggunakan software SPSS Versi 20. Hasil penelitian ini menunjukkan bahwa stabilitas keuangan tidak berpengaruh terhadap fraudulent financial reporting. Sementara itu, external pressure dan ineffective monitoring berpengaruh terhadap fraudulent financial reporting.
\end{abstract}

Kata Kunci: Stabilitas keuangan, external pressure, ineffective monitoring, fraudulent financial reporting 


\section{PENDAHULUAN}

Persaingan bisnis yang ketat menekan perusahaan untuk terus menghasilkan kinerja yang diharapkan. Selain itu, untuk tetap berkembang dan mempertahankan keberlangsungan usaha, pihak manajemen memerlukan dana tambahan dari investor (Santoso \& Surenggono, 2018). Hal ini yang mengakibatkan pihak manajemen melakukan tindakan kecurangan atau fraud untuk menutupi kinerja perusahaan yang kurang baik sehingga pendanaan dari investor maupun kreditor tetap mengalir dan agar nilai saham perusahaan tetap terjaga (Rezaee, 2002). Salah satu bentuk fraud yang dilakukan pihak manajemen adalah praktik kecurangan pelaporan keuangan perusahaan atau fraudulent financial reporting. Menurut American Institute of Certified Public Accountant (AICPA, 2002), fraudulent financial reporting merupakan penyajian maupun penggambaran kondisi keuangan suatu perusahaan dilakukan dengan tindakan salah saji yang secara sengaja dilakukan baik dengan menghilangkan suatu nilai atau jumlah maupun pengungkapan dari laporan keuangan dengan tujuan untuk mengelabui pengguna laporan keuangan tersebut sehingga dapat mengubah penilaian maupun keputusannya.

Praktik kecurangan dalam pelaporan keuangan adalah salah satu bentuk fraud yang paling sering terjadi (Yandiri \& Andini, 2020). Menurut survei Association of Certified Fraud Examiners (ACFE, 2019), persentase fraudulent financial reporting terjadi sebanyak 9,2\% kasus dari jenis fraud seperti korupsi dan penyalahgunaan aset. Selain itu, nilai kerugian akibat fraudulent financial reporting dengan nominal di bawah Rp 10 juta mencapai 67,4\%. Hal ini membuktikan bahwa kategori fraud ini merupakan kategori fraud yang paling kecil nilai frekuensinya dibandingkan kategori lain, namun kelak akan menghasilkan nilai kerugian yang lebih besar jika dibandingkan dengan kategori fraud lainnya. Kecurangan pelaporan keuangan terjadi sebanyak 2.690 kasus terhitung sejak Januari 2016 hingga Oktober 2017 (Association of Certified Fraud Examiners, 2018). Tindakan fraud tersebut akan berdampak besar pada bagian keuangan. Informasi yang disajikan dalam laporan keuangan tidak relevan dan andal dan akan berpengaruh terhadap pengambilan keputusan yang berpotensi merugikan pihak terkait.

ACFE Indonesia pada tahun 2019 mengumumkan survei bahwa perusahaan milik negara atau BUMN merupakan lembaga yang paling merugi akibat adanya fraud setelah pemerintahan. Sebesar 16\% BUMN ditaksir mengalami kerugian lebih dari Rp 10 miliar. Kasus fraudulent financial reporting yang terkenal di Indonesia dilakukan oleh salah satu BUMN adalah PT Garuda Indonesia (Persero), Tbk pada tahun 2019. Kecurangan pelaporan keuangan yang dilakukan adalah dengan melaporkan keuntungan pada Desember 2018 sekitar Rp 11 miliar, padahal pada tahun 2017 PT Garuda Indonesia mengalami kerugian hingga Rp 3 triliun (Mumpuni \& Jatiningsih, 2020). Lalu, ditemukan perjanjian kerja sama PT Garuda Indonesia dengan Mahata Aero Teknologi dalam Laporan Posisi Keuangan 2018 sebesar USD 239 juta. Pada kenyataannya, perjanjian kerja sama tersebut untuk 15 tahun dan dana belum diterima oleh PT Garuda Indonesia hingga akhir tahun 2018 sehingga tidak dapat dimasukkan ke dalam laporan tersebut.

Elemen risiko fraud tidak dapat diukur secara langsung (Apriliana \& Agustina, 2017). 
Pengukuran untuk mendeteksi fraud dilakukan dengan menggunakan proksi. Berdasarkan 3 faktor utama terjadinya fraud, maka pengukuran tekanan (pressure) diproksikan dengan stabilitas keuangan dan tekanan eksternal (external pressure), sedangkan untuk faktor kesempatan (opportunity) diproksikan dengan pengawasan yang tidak efektif (ineffective monitoring). Sementara itu, kecurangan laporan keuangan (fraudulent financial reporting) diukur dengan F-Score Model.

Penelitian terkait fraudulent financial reporting telah banyak dilakukan oleh beberapa peneliti terdahulu dengan beberapa hasil yang berbeda. Seperti penelitian yang dilakukan oleh Agusputri \& Sofie (2019) yang menyatakan bahwa stabilitas keuangan tidak berpengaruh terhadap fraudulent financial reporting sementara penelitian yang dilakukan oleh Felicia \& Tanusdjaja (2020) menemukan bahwa stabilitas keuangan berpengaruh signifikan negatif terhadap fraudulent financial reporting. Hasil penelitian yang dilakukan oleh Agusputri \& Sofie (2019) menjelaskan bahwa external pressure berpengaruh negatif terhadap fraudulent financial reporting sedangkan hasil penelitian yang dilakukan oleh Aulia et al., (2020) menyatakan bahwa external pressure tidak berpengaruh terhadap fraudulent financial reporting. Hasil penelitian yang dilakukan oleh Mumpuni \& Jatiningsih (2020) menyatakan bahwa ineffective monitoring tidak berpengaruh terhadap fraudulent financial reporting sedangkan hasil penelitian yang dilakukan oleh Agustina \& Pratomo (2019) menyebutkan bahwa secara simultan, kesempatan (diproksikan dengan ineffective monitoring) berpengaruh signifikan dan secara parsial berpengaruh positif signifikan terhadap fraudulent financial reporting.

Stabilitas keuangan diukur melalui persentase perubahan total aset (ACHANGE) sebab aset perusahaan yang tinggi dapat menjadi daya tarik bagi pihak investor dan perusahaan dianggap mampu memberikan return yang tinggi (Skousen et al., 2009). Sebaliknya, apabila total aset perusahaan dinilai rendah, investor akan menilai bahwa kinerja perusahaan kurang baik dan kurang stabilnya keuangan perusahaan. Dampak terhadap perusahaan adalah perusahaan mengalami risiko kurangnya dana investasi pada periode selanjutnya. Keuangan perusahaan yang tidak stabil menjadi tekanan dan dapat memicu pihak tertentu untuk melakukan tindakan rekayasa laporan keuangan agar perusahaan dapat terlihat maksimal mencapai kinerja terbaik. Hal ini sesuai dengan penelitian yang dilakukan oleh Alfian (2020) bahwa stabilitas keuangan berpengaruh positif terhadap fraudulent financial reporting. Berdasarkan uraian tersebut maka hipotesis pertama dalam penelitian ini adalah: $\mathrm{H}_{1}$ : Stabilitas keuangan berpengaruh terhadap fraudulent financial reporting.

External pressure adalah situasi saat perusahaan mengalami tekanan dari luar perusahaan. Skousen et al. (2009) menyatakan bahwa untuk mengatasi tekanan yang didapatkan perusahaan dari pihak eksternal, perusahaan harus mendapatkan sumber pembiayaan dari pihak eksternal agar perusahaan tetap kompetitif, termasuk pembiayaan dan pengeluaran riset atau modal. Tekanan pihak eksternal diproksikan dengan rasio leverage atau perbandingan antara total kewajiban (liabilities) dengan total aset. Kreditur sebagai pihak eksternal beranggapan apabila perusahaan memiliki leverage yang tinggi 
maka perusahaan tersebut memiliki utang yang besar dan memiliki risiko kredit yang tinggi sehingga kreditur akan merasa khawatir untuk memberikan pinjaman kepada perusahaan. Perusahaan pun akan mengalami kesulitan dalam memperoleh tambahan dana atau modal melalui pinjaman kepada kreditur. Risiko ini kemudian memicu pihak manajemen untuk melakukan tindakan fraud terhadap laporan keuangan. Berdasarkan uraian tersebut, maka hipotesis kedua dalam penelitian ini adalah:

$\mathrm{H}_{2}$ : External pressure berpengaruh terhadap fraudulent financial reporting.

SAS No. 99 dalam AICPA (2002) menyatakan bahwa salah satu peluang terjadinya frauduluent financial reporting adalah karena terjadinya ineffective monitoring. AICPA mendefinisikan pengawasan yang tidak efektif atau ineffective monitoring sebagai kondisi dimana kurangnya kontrol dan sistem internal perusahaan tidak berjalan efektif sehingga muncul kesempatan dalam melakukan tindakan fraud. Ineffective monitoring dapat terjadi karena dominasi oleh individu atau kelompok kecil dalam manajemen tanpa adanya kontrol dan pengawasan dewan, baik direksi maupun komite (Skousen et al., 2009). Lemahnya pengawasan ini memberikan kesempatan kepada pihak manajemen untuk melakukan tindakan kecurangan pelaporan keuangan dengan memanipulasi data yang ada. Berdasarkan uraian tersebut, maka hipotesis ketiga dalam penelitian ini adalah:

$\mathrm{H}_{3}$ : Ineffective monitoring berpengaruh terhadap fraudulent financial reporting.

\section{METODE}

\section{Populasi dan Sampel}

Metode yang digunakan dalam penelitian ini adalah metode penelitian kuantitatif. Populasi yang digunakan dalam penelitian ini adalah Badan Usaha Milik Negara (BUMN) yang listing di Bursa Efek Indonesia (BEI) periode 2017-2019. Metode pengambilan sampel menggunakan teknik purposive sampling, berdasarkan teknik purposive sampling, terdapat 21 perusahaan yang masuk dalam kriteria sampel. Pemilihan sampel berdasarkan kriteria yang telah ditentukan disajikan dalam tabel berikut:

Tabel 1 Pemilihan Sampel Berdasarkan Kriteria

\begin{tabular}{lc}
\hline \multicolumn{1}{c}{ Kriteria } & Jumlah \\
\hline BUMN yang terdaftar di BEI periode 2017-2019 & 24 \\
BUMN yang tidak menerbitkan laporan keuangan dan laporan tahunan pada tahun 2017-2019 & $(0)$ \\
BUMN yang menerbitkan laporan keuangan selain dengan mata uang Rupiah & $(3)$ \\
BUMN yang memiliki tahun tutup buku selain 31 Desember & $(0)$ \\
Laporan keuangan dan laporan tahunan yang tidak memiliki data-data terkait variabel & $(0)$ \\
BUMN yang dijadikan sampel penelitian & 21 \\
Jumlah sampel penelitian x $\mathbf{3}$ tahun & $\mathbf{6 3}$ \\
\hline
\end{tabular}

Sumber: Data diolah, 2021 


\section{Definisi Operasional Variabel}

Metode yang digunakan untuk mengukur indikasi kecurangan pada perusahaan adalah model perhitungan Fraud Score Model atau F-Score Model yang dikembangkan oleh Dechow et al. (2007). Harahap et al. (2017) menjelaskan bahwa perusahaan diprediksi melakukan fraud apabila hasil dari F-Score Model bernilai lebih dari 1. Tetapi perusahaan tidak bisa diprediksi melakukan fraud apabila hasil F-Score Model bernilai kurang dari 1. F-Score Model merupakan penjumlahan kualitas akrual (accrual quality) dan kinerja keuangan (financial performance) (Skousen et al., 2009). Perhitungan accrual quality diproksikan dengan RSST accrual (Richardson et al., 2006). Rumus untuk menghitung RSST accrual adalah:

$$
\text { RSST Accrual }=\frac{(\Delta \mathrm{WC}+\Delta \mathrm{NCO}+\Delta \mathrm{FIN})}{\mathrm{ATS}}
$$

Keterangan:

$\begin{array}{ll}\text { WC (Working Capital) } & : \text { (Current Assets - Current Liability) } \\ \text { NCO (Non Current Operating Accrual) }: & \text { (Total Assets - Current Assets - Investment } \\ & \begin{array}{l}\text { and Advances) }-(\text { Total Liabities }- \\ \text { Current Liabilities }- \text { Long Term Debt) }\end{array} \\ \text { FIN (Financial Accrual) } & :(\text { Total Investment }- \text { Total Liabilities }) \\ \text { ATS (Average Total Assets) } & : \frac{(\text { Beginning Total Assets }+ \text { End Total Assets) }}{2}\end{array}$

Richardson et al. (2006) juga menjelaskan perhitungan financial performance diproksikan dengan perubahan dalam akun penjualan tunai, perubahan dalam akun piutang, dan perubahan pada pajak dan pendapatan sebelum bunga (EBIT). Rumus untuk menghitung financial performance adalah:

Financial Performance $=$ Change in Receivables + Change in Inventories + Change in Cash Sales + Change in Earnings

Keterangan:

Change in Receivables : $\frac{\Delta \text { Receivables }}{\text { Average Total Assets }}$

Change in Inventories : $\frac{\Delta \text { Inventories }}{\text { Average Total Assets }}$

Change in Cash Sales : $\frac{\Delta \text { Sales }}{\text { Sales }(t)}-\frac{\Delta \text { Receivables }}{\text { Receivales }(t)}$

Change in Earnings $: \frac{\text { Earnings }(\mathrm{t})}{\text { Average Total Assets }(\mathrm{t})}-\frac{\text { Earnings }(\mathrm{t}-1)}{\text { Average Total Assets }(\mathrm{t}-1)}$

Berdasarkan penjelasan rumus accrual quality dan financial performance tersebut di atas, maka rumus untuk menghitung risiko fraudulent financial reporting pada perusahaan menggunakan F-Score Model adalah:

F-Score Model $=$ Accrual Quality + Financial Performance 
Stabilitas keuangan perusahaan dapat diukur menggunakan perbandingan total aset (ACHANGE) yang dimiliki berdasarkan pada pertumbuhan total aset perusahaan selama dua tahun (Skousen et al., 2009). Perhitungan ACHANGE adalah:

$$
\text { ACHANGE }=\frac{(\text { Total Aset }(\mathrm{t})-\text { Total Aset }(\mathrm{t}-1))}{\text { Total Aset }(\mathrm{t}-1)}
$$

Tekanan eksternal atau external pressure adalah suatu keadaan dimana pihak manajemen mendapatkan tekanan yang berlebihan untuk memenuhi keinginan pihak ketiga (Skousen et al., 2009). Manajemen dituntut untuk dapat memperoleh tambahan utang maupun sumber eksternal dan pembiayaan modal (ekuitas) agar perusahaan dapat tetap kompetitif dalam kegiatan operasionalnya. Kebutuhan pembiayaan eksternal tersebut terkait dengan kas yang dihasilkan dari pembiayaan melalui hutang (Skousen et al., 2009). Hal ini dapat dicerminkan dari leverage ratio, yaitu yang dimiliki oleh perusahaan.

$$
\text { Leverage }=\frac{\text { Total Liabilitas }}{\text { Total Aset }}
$$

Kesempatan untuk melakukan tindakan fraud akan lebih berpeluang dimanfaatkan apabila perusahaan memiliki sistem pengendalian internal yang lemah. (Setiawati \& Baningrum, 2018), Metode yang digunakan untuk mengukur ineffective monitoring dalam penelitian ini adalah menggunakan proksi rasio jumlah dewan komisaris independen (BDOUT) sesuai dengan penelitian (Skousen et al., 2008).

$$
\text { BDOUT }=\frac{\text { Jumlah Komisaris Independen }}{\text { Total Dewan Komisaris }}
$$

\section{Teknik Analisis Data}

Metode yang digunakan untuk menguji hipotesis dalam penelitian ini adalah dengan model regresi logistik (logistic regression). Model regresi logistik yang digunakan dalam penelitian ini adalah:

$$
\operatorname{Ln} \frac{P}{(1-P)}=\alpha_{0}+\beta 1 \mathrm{X} 1+\beta 2 \mathrm{X} 2+\beta 3 \mathrm{X} 3+\varepsilon
$$

Keterangan:

$\operatorname{Ln} \frac{P}{(1-P)}$ : Probabilitas perusahaan yang terdeteksi melakukan fraud

$\alpha_{0} \quad$ : Konstanta

$\beta 1,2,3$ : Koefisien variabel

X1 : Stabilitas Keuangan (ACHANGE)

X2 : External Pressure (LEVERAGE)

X3 : Ineffective Monitoring (BDOUT)

$\varepsilon \quad:$ error 


\section{HASIL DAN PEMBAHASAN}

Analisis statistik deskriptif dalam penelitian ini bertujuan untuk memberikan gambaran dari variabel penelitian dalam bentuk perhitungan statistif seperti mean, median, standar deviasi dan tabulasi data frekuensi yang akan ditampilkan sebagai berikut:

Tabel 2 Hasil Uji Descriptive Statistics

\begin{tabular}{lrrrrr}
\hline & N & Minimum & Maximum & Mean & Std. Deviation \\
\hline Fraudulent Financial Reporting & 63 & 0 & 1 &, 10 &, 296 \\
Stabilitas Keuangan & 63 &,- 0934 & 3,8065 &, 245624 &, 4877076 \\
External Pressure & 63 &, 2941 &, 8642 &, 614159 &, 1712461 \\
Ineffective Monitoring & 63 &, 2857 &, 7143 &, 430343 &, 1033266 \\
\hline Valid N (listwise) & 63 & & & & \\
\hline
\end{tabular}

Sumber: Data diolah, 2021

\section{Uji Kelayakan Model (Hosmer and Lemeshow's Goodness of Fit Test)}

Hasil uji kelayakan model disajikan pada tabel berikut:

Tabel 3 Hosmer and Lemeshow Test

\begin{tabular}{cccl}
\hline Step & Chi-square & df & Sig. \\
\hline 1 & 1,751 & 8 &, 988 \\
\hline
\end{tabular}

Sumber: Data diolah, 2021

Berdasarkan hasil pengujian yang disajikan dalam tabel 3, hasil dari Hosmer and Lemeshow's Goodness of Fit Test pada nilai Chi Square sebesar 1,751 dengan nilai signifikansi sebesar 0,988. Hasil tersebut menunjukkan nilai signifikansi lebih besar dari 0,05 yang berarti Ho diterima dan berarti bahwa tidak terdapat perbedaan antara klasifikasi yang diprediksi dengan klasifikasi yang diamati, sehingga model regresi dapat digunakan untuk analisis selanjutnya.

\section{Uji Log Likelihood (-2 log Likelihood)}

Berdasarkan hasil pengujian yang disajikan dalam tabel 4, hasil dari -2 Log Likelihood dapat digunakan untuk melihat model regresi yang baik pada pendeteksian fraudulent financial reporting. Hasil perhitungan -2 log Likelihood pada blok pertama (block number 0) dan nilainya dapat dilihat pada tabel 4 berikut: 
Tabel 4 Iteration History

\begin{tabular}{llcc}
\hline Iteration & $\mathbf{- 2}$ Log likelihood & $\begin{array}{c}\text { Coefficients } \\
\text { Constant }\end{array}$ \\
\hline & 1 & 42,200 & $-1,619$ \\
Step 0 & 2 & 39,713 & $-2,127$ \\
& 3 & 39,626 & $-2,245$ \\
& 4 & 39,626 & $-2,251$ \\
& 5 & 39,626 & $-2,251$ \\
\hline
\end{tabular}

Sumber: Data diolah, 2021

Hasil perhitungan -2 Log Likelihood pada blok pertama (block number 0) memiliki nilai -2 Log Likelihood sebesar 39,626. Kemudian hasil perhitungan nilai -2 Log Likelihood pada blok kedua (block number 1) dan nilainya disajikan pada tabel 5 berikut:

Tabel 5 Iteration History

\begin{tabular}{ccccccc}
\hline \multirow{2}{*}{ Iteration } & \multirow{2}{*}{$\mathbf{- 2}$ Log likelihood } & \multicolumn{5}{c}{ Coefficients } \\
\cline { 4 - 6 } & 1 & 34,397 & Constant & ACHANGE & LEV & BDOUT \\
\hline & 2 & 26,289 & $-1,226$ &, 869 & $-3,032$ & 2,918 \\
& 3 & 23,001 & $-1,426$ & 1,329 & $-6,914$ & 6,829 \\
& 4 & 21,847 & $-1,302$ & 1,770 & $-11,469$ & 11,347 \\
Step 1 & 5 & 21,587 &,- 977 & 2,172 & $-15,705$ & 14,821 \\
& 6 & 21,565 &,- 830 & 2,444 & $-18,694$ & 16,773 \\
& 7 & 21,565 &,- 815 & 2,540 & $-19,832$ & 17,452 \\
& 8 & 21,565 &,- 815 & 2,549 & $-19,951$ & 17,524 \\
& 9 & 21,565 &,- 815 & 2,549 & $-19,953$ & 17,524 \\
& & & & 2,549 & $-19,953$ & 17,524 \\
\hline
\end{tabular}

Sumber: Data diolah, 2021

Hasil perhitungan nilai -2 Log Likelihood pada blok kedua (block number 1) terlihat bahwa nilai -2 Log Likelihood sebesar 21,565 atau terjadi penurunan pada blok kedua (block number 1). Hal tersebut menunjukkan bahwa terdapat penurunan nilai -2 Log Likelihood sehingga dapat ditarik kesimpulan bahwa model dinilai layak dan mampu untuk menjelaskan hubungan variabel bebas (dependen) dengan variabel terikat (independen).

Sementara itu, hasil uji koefisien determinasi disajikan pada tabel berikut:

Tabel 6 Uji Cox and Snell's dan Nagelkereke's R Square

\begin{tabular}{cccc}
\hline Step & $\mathbf{- 2}$ Log likelihood & Cox \& Snell R Square & Nagelkerke R Square \\
\hline 1 & 21,565 &, 249 &, 534 \\
\hline
\end{tabular}

Sumber: Data diolah, 2021 
Berdasarkan data pada tabel 6, nilai Nagelkerke $R$ Square adalah sebesar 0,534 atau $53,4 \%$ yang berarti tiga variabel independen (stabilitas keuangan, external pressure, dan ineffective monitoring) yang digunakan dalam penelitian ini dapat menjelaskan variabel dependen (fraudulent financial reporting) sebesar 53,4\% dan sisanya sebesar 46,6\% dijelaskan oleh faktor-faktor lain yang tidak diajukan dalam penelitian ini.

Ketepatan prediksi klasifikasi dalam penelitian ini dapat diamati pada tabel 7 berikut ini:

Tabel 7 Prediksi Klasifikasi

\begin{tabular}{|c|c|c|c|c|c|}
\hline & \multirow{3}{*}{ Observed } & & \multicolumn{3}{|c|}{ Predicted } \\
\hline & & & \multicolumn{2}{|c|}{$\begin{array}{c}\text { Fraudulent Financial } \\
\text { Reporting }\end{array}$} & \multirow{2}{*}{$\begin{array}{l}\text { Percentage } \\
\text { Correct }\end{array}$} \\
\hline & & & Tidak Fraud & Fraud & \\
\hline \multirow{3}{*}{ Step 1} & Fraudulent Financial & Tidak Fraud & 56 & 1 & 98,2 \\
\hline & Reporting & Fraud & 4 & 2 & 33,3 \\
\hline & Overall Percentage & & & & 92,1 \\
\hline
\end{tabular}

Sumber: Data diolah, 2021

Berdasarkan Classification Table pada tabel 7, jumlah sampel yang diprediksi tidak melakukan fraud sebanyak 57 perusahaan. Hasil ini didapatkan dari penjumlahan sampel yakni 56 perusahaan tidak melakukan fraud dan 1 perusahaan yang diprediksi tidak melakukan fraud tetapi pada kenyataannya melakukan tindakan fraud. Kekuatan prediksi model perusahaan yang dinyatakan tidak melakukan tindakan fraud adalah sebesar 98,2\% yang berarti bahwa dengan model regresi yang digunakan dalam penelitian ini, terdapat 62 perusahaan dari total 63 perusahaan tidak melakukan tindakan fraud. Tabel 4.13 juga menjelaskan bahwa jumlah sampel yang diprediksi melakukan tindakan fraud sebanyak 6 perusahaan. Hasil ini didapatkan dari penjumlahan sampel yakni 4 perusahaan yang diprediksi melakukan tindakan fraud tetapi pada kenyataannya tidak melakukan tindakan fraud dan 2 perusahaan yang melakukan tindakan fraud. Kekuatan prediksi model perusahaan yang dinyatakan melakukan tindakan fraud adalah sebesar 33,3\% yang berarti bahwa dengan model regresi yang digunakan dalam penelitian ini, terdapat 21 perusahaan dari total 63 perusahaan melakukan tindakan fraud. Nilai overall percentage sebesar 92,1 yang berarti ketepatan model penelitian ini adalah sebesar 92,1\%.

Hasil analisis data dengan menggunakan uji statistik deskriptif menjelaskan bahwa fradulent financial reporting yang diukur dengan F-Score Model menunjukkan nilai minimum sebesar 0 dan nilai maksimum sebesar 1 . Nilai rata-rata (mean) untuk variabel fraudulent financial reporting sebesar 0,10 dengan tingkat penyimpangan (standard deviation) data sebesar 0,296. Stabilitas keuangan yang diukur dengan rasio total aset (ACHANGE) menunjukkan nilai minimum sebesar -0,0934 dan nilai maksimum sebesar 3,8065. Nilai rata-rata (mean) untuk variabel stabilitas keuangan sebesar 0,245624 dengan tingkat penyimpangan (standard deviation) data sebesar 0,4877076. External pressure yang diukur dengan perbandingan antara total kewajiban atau liabillitas dengan total aset (LEV) menunjukkan nilai minimum 
sebesar 0,2941 dan nilai maksimum sebesar 0,8642. Nilai rata-rata (mean) untuk variabel external pressure sebesar 0,614159 dengan tingkat penyimpangan (standard deviation) data sebesar 0,1712461. Ineffective monitoring yang diukur dengan rasio jumlah dewan komisaris independen (BDOUT) menunjukkan nilai minimum sebesar 0,2857 dan nilai maksimum sebesar 0,7143. Nilai rata-rata (mean) untuk variabel external pressure sebesar 0,430343 dengan tingkat penyimpangan (standard deviation) data sebesar 0,1033266.

Berikut ini adalah hasil uji regresi yang dilakukan:

Tabel 8 Variables in the Equation

\begin{tabular}{rlrrrrrr}
\hline & & B & S.E. & Wald & df & Sig. & \multicolumn{1}{c}{$\operatorname{Exp(B)}$} \\
\hline \multirow{2}{*}{ Step 1 } & ACHANGE & 2,549 & 2,329 & 1,198 & 1 &, 274 & 12,797 \\
& LEV & $-19,953$ & 9,262 & 4,641 & 1 &, 031 &, 000 \\
& BDOUT & 17,524 & 8,368 & 4,386 & 1 &, 036 & 40802447,367 \\
& Constant &,- 815 & 2,845 &, 082 & 1 &, 775 &, 443 \\
\hline
\end{tabular}

Sumber: Data diolah, 2021

Berdasarkan informasi yang disajikan pada tabel diatas, persamaan regresi logistik antara variabel independen $(\mathrm{X})$ terhadap variabel dependen $(\mathrm{Y})$ yang dapat diformulasikan dalam bentuk persamaan adalah sebagai berikut:

$$
\operatorname{Ln} \frac{P}{(1-P)}=-0.815+2.549 X 1-19.953 X 2+17.524 X 3+\varepsilon
$$

Keterangan:

$\operatorname{Ln} \frac{P}{(1-P)}$ : Probabilitas perusahaan yang terdeteksi melakukan fraud

$\alpha_{0} \quad$ : Konstanta

$\beta 1,2,3 \quad$ : Koefisien variabel

X1 : Stabilitas Keuangan (ACHANGE)

X2 : External Pressure (LEVERAGE)

X3 : Ineffective Monitoring (BDOUT)

$\varepsilon \quad:$ error

Hasil uji hipotesis pertama menunjukkan hasil bahwa tidak terdapat pengaruh antara stabilitas keuangan (X1) dengan fraudulent financial reporting. Pengujian hipotesis ini ditunjukkan dengan nilai koefisien sebesar 2,549 dengan tingkat signifikansi lebih besar dibandingkan dengan nilai signifikansi yang ditetapkan yaitu 0,274 $>0,05$, yang berarti $\mathrm{H}_{1}$ ditolak. Artinya bahwa variabel stabilitas keuangan tidak berpengaruh terhadap fraudulent financial reporting. Berdasarkan hasil analisis hipotesis pertama yang menguji pengaruh stabilitas keuangan terhadap fraudulent financial reporting yang diukur dengan persentase perubahan total aset (ACHANGE), diketahui bahwa stabilitas keuangan tidak berpengaruh terhadap tindakan fraudulent financial reporting. Stabilitas keuangan dapat dilihat dari 
perubahan total aset dimana apabila perusahaan memiliki nilai aset yang kecil, maka perusahaan dianggap memiliki kondisi keuangan yang tidak stabil. Hasil penelitian ini sesuai dengan pernyataan Agusputri \& Sofie (2019) bahwa tindakan fraudulent financial reproting yang dilakukan oleh pihak manajer untuk menunjukkan kepada investor bahwa perusahaan memiliki kinerja yang baik akan memperparah kondisi keuangan perusahaan dimasa mendatang. Hasil penelitian ini mendukung hasil penelitian yang dilakukan oleh Agusputri \& Sofie (2019) dan penelitian Aulia et al. (2020) yang menjelaskan bahwa stabilitas keuangan tidak berpengaruh terhadap fraudulent financial reporting. Namun hasil penelitian ini tidak mendukung penelitian yang dilakukan oleh Felicia \& Tanusdjaja (2020) dan Alfian (2020) yang menyatakan bahwa stabilitas keuangan berpengaruh terhadap fraudulent financial reporting.

Hasil uji hipotesis kedua menunjukkan hasil bahwa terdapat pengaruh antara external pressure (X2) dengan fraudulent financial reporting. Pengujian hipotesis ini ditunjukkan dengan nilai koefisien sebesar -19,953 dengan tingkat signifikansi lebih kecil dibandingkan dengan nilai signifikansi yang ditetapkan yaitu 0,031<0,05, yang berarti H2 diterima. Artinya bahwa variabel external pressure berpengaruh terhadap fraudulent financial reporting. Berdasarkan hasil analisis hipotesis kedua yang menguji pengaruh external pressure terhadap fraudulent financial reporting yang diukur dengan perbandingan total kewajiban dengan total aset (LEVERAGE), diketahui bahwa external pressure berpengaruh terhadap tindakan fraudulent financial reporting pada BUMN. Hal ini dikarenakan pihak manajemen akan berusaha untuk mendapatkan sumber pembiayaan dari pihak eksternal agar perusahaan tetap kompetitif, termasuk pembiayaan dan pengeluaran riset atau modal (Skousen et al., 2009). Perusahaan pun akan mengalami kesulitan dalam memperoleh tambahan dana atau modal melalui pinjaman kepada kreditur. Risiko ini kemudian memicu pihak manajemen untuk melakukan tindakan fraud terhadap laporan keuangan. Hasil penelitian ini mendukung hasil penelitian yang dilakukan oleh Agusputri \& Sofie (2019) dan Agustina \& Pratomo (2019) yang menjelaskan bahwa external pressure berpengaruh negatif terhadap fraudulent financial reporting. Namun hasil penelitian ini tidak mendukung penelitian yang dilakukan oleh Aulia et al., (2020) yang menyatakan bahwa external pressure tidak berpengaruh terhadap fraudulent financial reporting.

Hasil uji hipotesis ketiga menunjukkan hasil bahwa terdapat pengaruh antara ineffective monitoring (X3) dengan fraudulent financial reporting. Pengujian hipotesis ini ditunjukkan dengan nilai koefisien sebesar 17,524 dengan tingkat signifikansi lebih kecil dibandingkan dengan nilai signifikansi yang ditetapkan yaitu 0,036 < 0,05, yang berarti H3 diterima. Artinya bahwa variabel ineffective monitoring berpengaruh terhadap fraudulent financial reporting. Berdasarkan hasil analisis hipotesis ketiga yang menguji pengaruh ineffective monitoring terhadap fraudulent financial reporting yang diukur dengan rasio jumlah dewan komisaris independen (BDOUT), diketahui bahwa ineffective monitoring berpengaruh terhadap tindakan fraudulent financial reporting. AICPA yang mendefinisikan pengawasan yang tidak efektif atau ineffective monitoring sebagai kondisi dimana kurangnya kontrol dan sistem internal perusahaan tidak berjalan efektif sehingga muncul kesempatan dalam melakukan tindakan fraud. Menurut Setiawati \& Baningrum (2018), kesempatan untuk melakukan 
tindakan fraud akan lebih berpeluang dimanfaatkan apabila perusahaan memiliki sistem pengendalian internal yang lemah. Hasil penelitian ini mendukung hasil penelitian yang dilakukan oleh Agusputri \& Sofie (2019) dan Agustina \& Pratomo (2019) yang menjelaskan bahwa ineffective monitoring berpengaruh positif terhadap fraudulent financial reporting. Namun hasil penelitian ini tidak mendukung penelitian yang dilakukan oleh Mumpuni \& Jatiningsih (2020) yang menyatakan bahwa ineffective monitoring tidak berpengaruh terhadap fraudulent financial reporting.

\section{SIMPULAN}

Berdasarkan hasil penelitian dan pembahasan yang telah dikemukakan sebelumnya, maka dapat disimpulkan bahwa stabilitas keuangan tidak berpengaruh terhadap fraudulent financial reporting. BUMN memiliki akses untuk mendapatkan pendanaan dari pihak bank maupun pasar modal sehingga dapat menutupi kondisi keuangan perusahaan yang tidak stabil tanpa perlu melakukan tindakan fraudulent financial reporting. External pressure dan ineffective monitoring berpengaruh terhadap fraudulent financial reporting. Kreditur sebagai pihak eksternal beranggapan apabila BUMN maupun perusahaan lain memiliki leverage yang tinggi maka perusahaan tersebut memiliki utang yang besar dan memiliki risiko kredit yang tinggi sehingga kreditur akan merasa khawatir untuk memberikan pinjaman kepada perusahaan. Perusahaan pun akan mengalami kesulitan dalam memperoleh tambahan dana atau modal melalui pinjaman kepada kreditur. Risiko ini kemudian memicu pihak manajemen untuk melakukan tindakan fraud terhadap laporan keuangan. Semua BUMN memiliki komisaris independen sebagai bagian dari sistem kontrol dan pengawasan perusahaan yang jauh dari pengaruh pihak-pihak tertentu. Tingginya efektivitas pengawasan komisaris independen dalam perusahaan akan mengurangi kesempatan pihak manajemen untuk melakukan tindakan fraud.

Implikasi dari hasil diatas adalah pada umumnya, kreditor maupun investor akan melihat utang yang dimiliki oleh perusahaan. Jika utang yang dimiliki oleh perusahaan terlalu besar, pihak kreditur maupun investor tidak akan tertarik untuk memberikan pinjaman atau berinvestasi pada perusahaan tersebut. Selain itu, manajemen kerap mendapatkan tekanan agar dapat mengelola aset perusahaan dengan baik agar menghasilkan laba yang tinggi dan berpengaruh terhadap return yang tinggi bagi para investor. Salah satu faktor yang menyebabkan manajemen melakukan tindakan fraudulent financial reporting adalah kurang efektifnya pengendalian dan pengawasan dari perusahaan sehingga dapat memunculkan kesempatan bagi pihak manajemen. Kesempatan ini akan dimanfaatkan oleh manajemen dengan melakukan tindakan fraud secara sembunyi-sembunyi agar tidak diketahui.

\section{PUSTAKA ACUAN}

Agusputri, H., \& Sofie. (2019). Faktor-Faktor yang Berpengaruh terhadap Fraudulent Financial Reporting dengan Menggunakan Analisis Fraud Pentagon. Jurnal Informasi Perpajakan, Akuntansi Dan Keuangan Publik, 14(2), 105-125. 
Agustina, R., \& Pratomo, D. (2019). Pengaruh Fraud Pentagon dalam Mendeteksi Kecurangan Pelaporan Keuangan. Jurnal Ilmiah Manajemen, Ekonomi, \& Akuntansi, 3(1), 44-62.

Alfian, N. (2020). Pengaruh Financial Stability, Change in Auditors, DChange, CEO's Pict pada Fraud dalam Perspektif Fraud Pentagon. Jurnal Akuntansi Dan Investasi, 4(1), 69-80.

American Institute of Certified Public Accountant (AICPA). (2002). Statement on Auditing Standards (SAS) No. 99: Consideration of Fraud in a Financial Statement Audit. AICPA.

Apriliana, S., \& Agustina, L. (2017). The Analysis of Fraudulent Financial Reporting Determinant through Fraud Pentagon Approach. Jurnal Dinamika Akuntansi, 9(2), 154-165.

Association of Certified Fraud Examiners (ACFE). (2018). Global Study on Occupational Fraud and Abuse.

Association of Certified Fraud Examiners (ACFE). (2019). Survei Fraud Indonesia.

Aulia, I., Fatmala, K., Putri, A. ., Pratiwi, A., Muslim, A. ., \& Manda, G. . (2020). Analisis Pengaruh Stabilitas Keuangan dan Tekanan Eksternal terhadap Kecurangan Laporan Keuangan. Jurnal Ilmiah Pena, 12(1).

Dechow, P. ., Ge, W., Larson, C. ., Sloan, R. ., \& Investors, B. . (2007). Predicting Material Accounting Manipulations. Ann Arbor.

Felicia, C., \& Tanusdjaja, H. (2020). Pengaruh Faktor-Faktor Tertentu terhadap Fraudulent Financial Statement pada Perusahaan Manufaktur yang Terdaftar di Bursa Efek Indonesia Tahun 2016-2018. Jurnal Multiparadigma Akuntansi Tarumanegara, 2, 1745-1752.

Harahap, A. T. D., Majidah, \& Triyanto, N. D. (2017). Pengujian Fraud Diamond Dalam Kecurangan Laporan Keuangan (Studi Kasus Pada Perusahaan Pertambangan yang terdaftar di Bursa Efek Indonesia Tahun 2011- 2015). E-Proceeding of Management, $4(1), 420-427$.

Mumpuni, P. N. ., \& Jatiningsih, D. E. . (2020). Deteksi Kecurangan pada Badan Usaha Milik Negara : Pendekatan Fraud Pentagon Theory. The 3rd Febenefecium.

Rezaee, Z. (2002). Financial Statement Fraud Prevention and Detection. John Wiley \& Sons, Inc. John Wiley \& Sons, Inc.

Richardson, S. A., Sloan, R. G., Soliman, M. T., \& Tuna, I. (2006). The Implications of Accounting Disortions and Growth for Accruals and Profitability. The Accounting Review, 81(3), 713-743.

Santoso, N. T., \& Surenggono. (2018). Predicting Financial Statement Fraud with Fraud Diamond Model of Manufacturing Companies Listed in Indonesia. State-of-the-Art Theories and Empirical Evidence, 151-163.

Setiawati, E., \& Baningrum, R. M. (2018). Deteksi Fraudulent Financial Reporting Menggunakan Analisis Fraud Pentagon: Studi Kasus Pada Perusahaan Manufaktur Yang Listed Di BEI Tahun 2014-2016. Riset Akuntansi Dan Keuangan Indonesia, 3(2), 91-106.

Skousen, C. J., Smith, K. R., \& Charlotte J, W. (2009). Detecting and Predecting Financial Statement Fraud: The Effectiveness of The Fraud Triangle and SAS No. 99. Corporate Governance and Firm Performance Advances in Financial Economics, 53-81. 
Yandiri, D. ., \& Andini, I. . (2020). Analisis Fraud Pentagon Terhadap Tindakan Kecurangan Laporan Keuangan dengan Penggunaan Model Beneish. Ganaya Jayapangus Press, 3(2), 441-450. 